\title{
THIRD CORONARY ARTERY: A CADAVERIC STUDY
}

\section{Jyothi Lakshmi G.L. *1, Vineesh V ${ }^{2}$, Dini Mathew ${ }^{3}$.}

${ }^{* 1}$ Assistant Professor, Department of Anatomy, Rajarajeshwari M edical College and Hospital, Bangalore, Karnataka, India.

${ }^{2}$ Tutor, Department of Anatomy, Rajarajeshwari Medical College and Hospital, Bangalore, Karnataka, India.

${ }^{3}$ Postgraduate, Department of Anatomy, Rajarajeshwari Medical College and Hospital, Bangalore, Karnataka, India.

\section{ABSTRACT}

Introduction: The human heart is vascularised by the Third coronary artery apart from the right and the left coronary arteries. The Third coronary artery, also called Supernumerary coronary artery takes origin from the anterior aortic sinus of the heart. It plays a significant role in collateral circulation of heart in conditions of chronic hypoxia.

Aim: The aim of the study is to delineate different morphological patterns of the Third coronary artery anatomy in adult human cadaveric hearts by dissection. The origin, course, branching of Third coronary artery (TCA) were studied in detail.

Materials and Methods: The study was carried out on 50 formalin fixed normal adult human hearts obtained from the Department of Anatomy, Rajarajeshwari M edical College and Hospital. Specimens with gross congenital anomalies were excluded from the study. The right coronary artery, left coronary artery and the third coronary artery were carefully dissected and observations noted.

Results: The frequency of third coronary artery observed in our study is 30\%. The TCA and right coronary artery originated from a common ostium in the Anterior aortic sinus in most of the cases. We observed 2 third coronary arteries arising from anterior aortic sinus in 2 specimens.The third coronary artery frequently bifurcated to supply the pulmonary infundibulum and anterior wall of the right ventricle. It also reached the inferior border supplying the apex in $6 \%$ of the cases.

Conclusions: The area of perfusion of the Third coronary artery is variable and may be more extensive than usual in some individuals. Well developed collateral circulation through TCA may allow diagnostic and therapeutic interventions in patients with coronary artery disease. The variant anatomy and the significant contribution of TCA to coronary perfusion necessitates the selective visualization and functional assessment of TCA in patients with coronary artery disease.

KEY WORDS: Third Coronary Artery, Frequency, Collateral Circulation, Dissection.

Address for correspondence: Dr.Jyothi Lakshmi G.L. , \#113, Second floor, Bhargava, Ramarao layout, Kathriguppe, Banashankari 3rd stage, Bangalore, Karnataka, India.

E-M ail: drjyothilakshmigl@gmail.com

\begin{tabular}{|c|c|c|}
\hline \multicolumn{3}{|c|}{ Access this Article online } \\
\hline \multirow{3}{*}{ 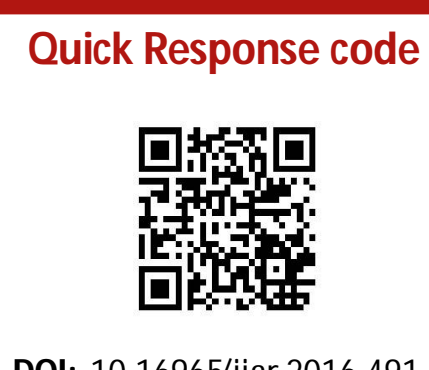 } & \multicolumn{2}{|c|}{$\begin{array}{c}\text { Web site: International Journal of Anatomy and Research } \\
\text { ISSN 2321-4287 } \\
\text { www.ijmhr.org/ijar.htm }\end{array}$} \\
\hline & $\begin{array}{l}\text { Received: } 29 \text { Nov } 2016 \\
\text { Peer Review: } 29 \text { Nov } 2016\end{array}$ & $\begin{array}{l}\text { Accepted: } 04 \text { Jan } 2017 \\
\text { Published (0): } 31 \text { Jan } 2017\end{array}$ \\
\hline & Revised: None & Published (P): 31 Jan 2017 \\
\hline
\end{tabular}

\section{INTRODUCTION}

The human heart is vascularised by the Third coronary artery apart from the right and the left coronary arteries. The first branch of the right 
coronary artery is the conus artery .This branch may arise separately from the anterior aortic sinus in $36 \%$ of the individuals which is sometimes termed a 'Third coronary' artery (TCA). It ramifies anteriorly on the lowest part of pulmonary conus and upper part of right ventricle [1]. It is also referred to as supernumerary artery but the term Third coronary artery is more suitable to clearly differentiate it from the conus branch of right coronary artery[2]. It plays a significant role in collateral circulation of heart as it frequently anastomoses with anterior interventricular branch of left coronary artery $[2,3]$. The extensive collateral circulation by the conus artery in patients with Coronary artery disease has been described in the literature[4,5,]. Researchers have stressed the importance of visualizing conus artery in coronary angiograms $[6,7]$. We undertook this study to delineate the different morphological patterns of the third coronary artery.

Aim: To delineate different morphological patterns of the third coronary artery anatomy in adult human cadaveric hearts by dissection. The origin, course, branching of Third coronary artery were studied in detail.

\section{MATERIALS AND METHODS}

The study was carried out on 50 formalin fixed normal adult human hearts obtained from the Department of Anatomy, Rajarajeshwari Medical College and Hospital. Specimens with gross congenital anomalies were excluded from the study. Approval from the Institutional Ethics committee was taken for the study. The right coronary artery, left coronary artery and the third coronary artery were carefully dissected and observations noted. To visualize the ostium, the ascending aorta was transversely sectioned $1 \mathrm{~cm}$ above the aortic leaflets and then the aorta was longitudinally sectioned along the posterior aortic sinus.

\section{RESULTS}

The third coronary artery was observed in 15 (30\%) out of 50 of the specimens. In 13 of the cases, the third coronary artery and the right coronary artery were found to be arising from a common ostium in the anterior aortic sinus (Figure 1). The third coronary artery took origin from a separate ostium in the anterior aortic sinus in 2 of the cases(Figure 2) and in both the cases, the orifice was located to the left of the orifice of the right coronary artery.

The third coronary artery, after taking origin from the Anterior aortic sinus, passed downwards and to the left through the subepicardial adipose tissue of the coronary sulcus for a short distance. After leaving the coronary sulcus, it ran on the anterior wall of the right ventricle to reach the pulmonary conus. It often ended by dividing into an upper branch and a lower longer branch.

The upper branch is smaller and shorter; ended by supplying the pulmonary infundibulum in most of the cases(Figure 3). The extent of the lower branch was found to be variable. In 5 of the specimens the lower branch extended till the Infundibulum, in 7 of the cases it extended till the anterior wall of the right ventricle(Figure 4 ) and in 3 cases it reached the inferior border of the right ventricle.

The third coronary artery started as a branch of small caliber in most of the cases. However, during our study we came across a third coronary artery of large caliber. In this case, the upper smaller branch supplied the pulmonary conus. The lower larger branch descended on the sternocostal surface of the heart directed towards the apex and divided into 3 branches which reached the inferior border of the heart (Figure 5).

In 1 specimen, two third coronary arteries and the right coronary artery took origin from a common ostium in the Anterior aortic sinus (Figure 6).

We also observed that the third coronary artery passed under myocardial bridges in 2 cases (Figure 7).

The observations of our study are summarized in Table no.1.

Table 1: Observations in the present study.

\begin{tabular}{|l|c|}
\hline \multicolumn{1}{|c|}{ Third coronary artery } & No of specimens \\
\hline Frequency & $15(30 \%)$ \\
\hline Origin from a common ostium in the AAS & $13(26 \%)$ \\
\hline Origin from a separate ostium in the AAS & $2(4 \%)$ \\
\hline The third coronary artery extending & $5(10 \%)$ \\
\hline Till the Infundibulum of right ventricle & $7(14 \%)$ \\
\hline Till the upper part of the anterior wall of right ventricle & $3(6 \%)$ \\
\hline Till the inferior border of right ventricle & $2(4 \%)$ \\
\hline Myocardial bridge along the course of the TCA & $1(2 \%)$ \\
\hline 2 TCAs from a common ostium in AAS &
\end{tabular}


Fig. 1: Origin of the Third coronary artery and Right coronary artery from a common ostium.

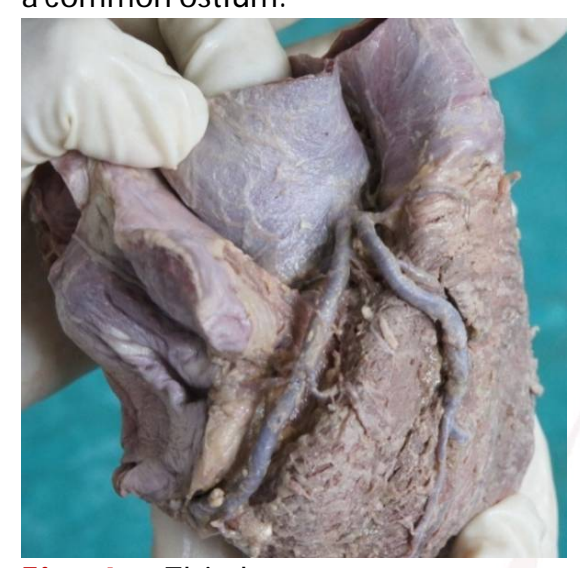

Fig. 4: Third coronary artery supplying the anterior wall of right ventricle.

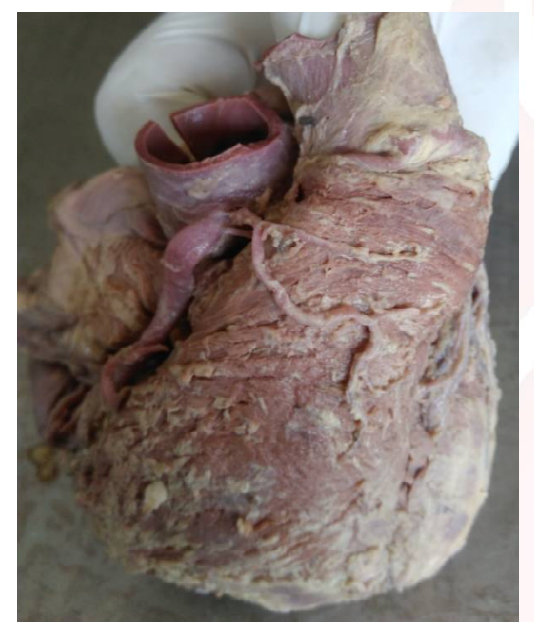

Fig. 7: A branch of third coronary artery passing under a myocardial bridge.

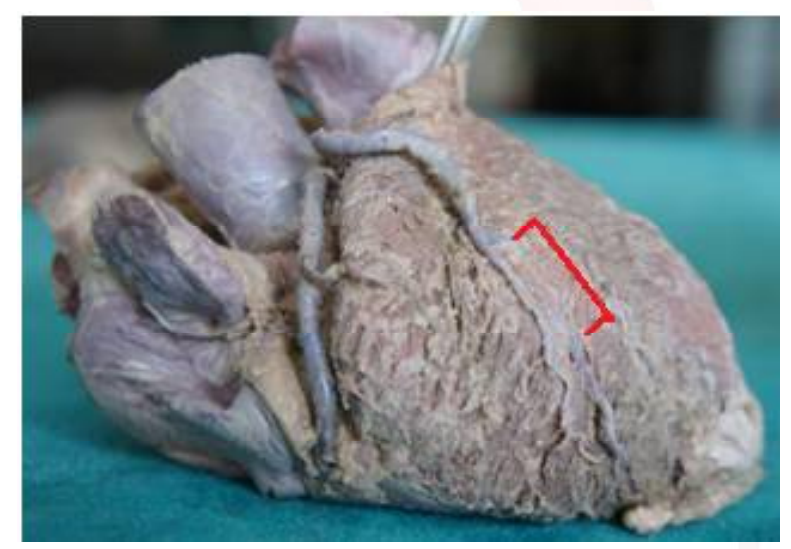

\section{DISCUSSION}

The first branch of the right coronary artery is the conus artery .This branch may arise separately from the anterior aortic sinus in $36 \%$ of the individuals which is sometimes termed a 'third coronary' artery. It ramifies anteriorly on the lowest part of pulmonary conus and upper part of right ventricle. It may anastomose with border of the heart.
Fig. 3: Third coronary artery supplying the infundibulum of the right ventricle.
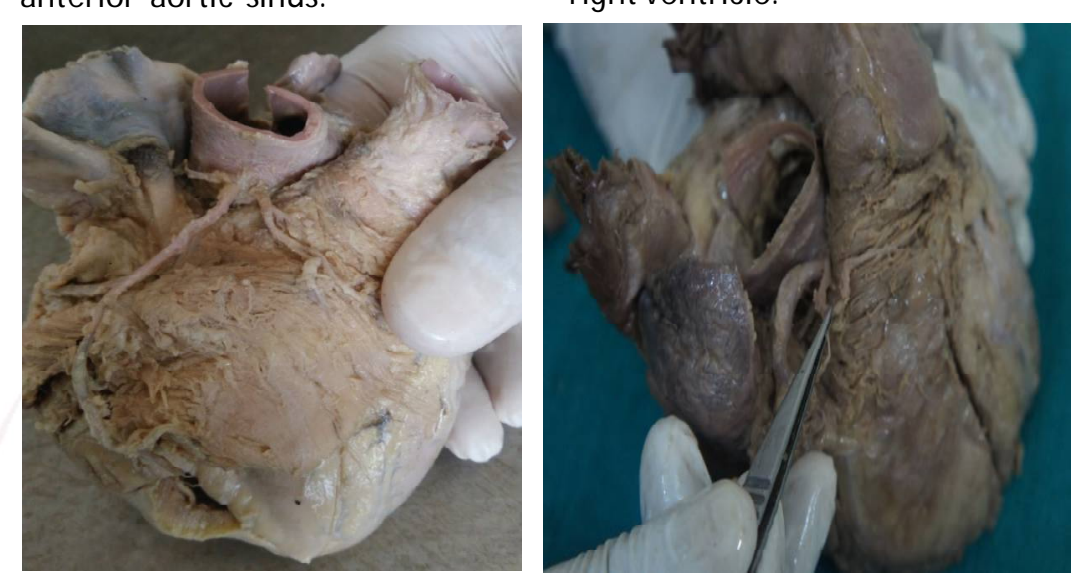

Branches of the Third coronary Fig. 6: 2 Third coronary arteries and right

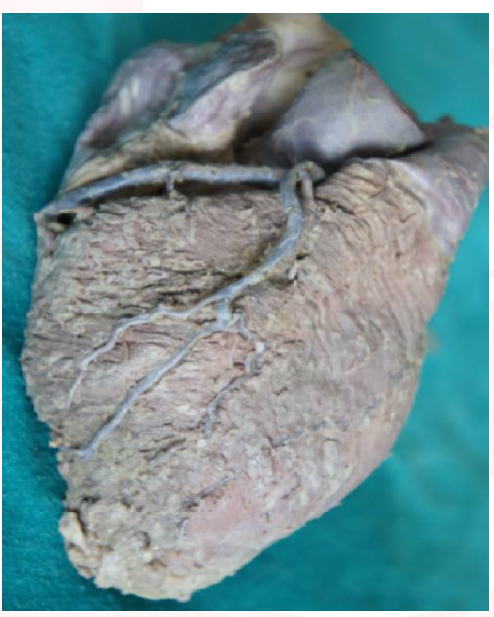
ostium in the anterior aortic sinus.

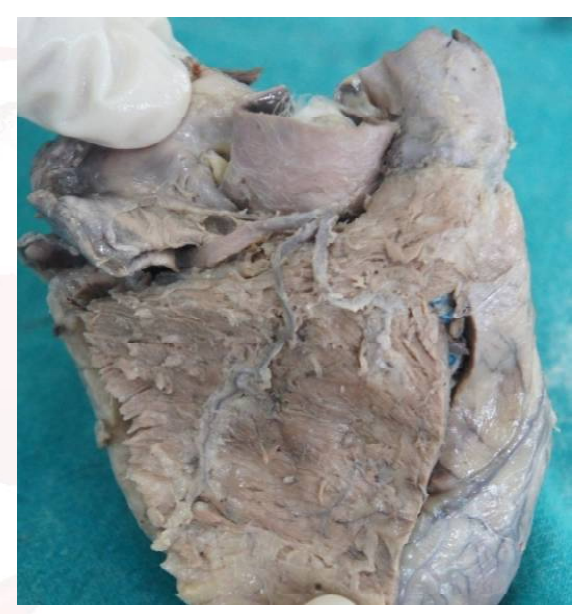

a similar left coronary branch from the left anterior descending artery to form the annulus of Vieussens, which is a tenuous anastomotic circle around right ventricular outflow tract [1]. Coronary vessel development is an example of vasculogenesis followed by angiogenesis [8]. According to the literature, major coronary arteries could be seen in the aortic wall prior to the emergence of coronary ostia , thus suggesting an ingrowth rather than outgrowth of these vessels[9].

Anastomosis between right and left coronary arteries are abundant during fetal life, but are much reduced by the end of first year of life. Anastomoses providing collateral circulation may become prominent in conditions of hypoxia and coronary artery disease. Anastomoses seem to be more effective in slowly progressive pathological conditions[1].

Anatomy of the TCA has been studied with different methods such as classical dissection, 
Coronary CT angiograms studies, Ostium recanalisation with polyester synthetic resin [10-14].

The frequency of the Third Coronary artery in various studies is compared in the Table 2 below.

Table 2: Comparision of frequency of the Third coronary artery in different studies.

\begin{tabular}{|l|c|}
\hline \multicolumn{1}{|c|}{ Author } & $\begin{array}{c}\text { Frequency of occurrence } \\
\text { of TCA (\%) }\end{array}$ \\
\hline Olabu et al [3] & 35.1 \\
\hline Lujinovic et al [2] & 32 \\
\hline Apsara [11] & 28 \\
\hline Kalpana [12] & 24 \\
\hline Ballasteros et al [14] & 25.8 \\
\hline Kulkarni JP [15] & 8 \\
\hline Present study & 30 \\
\hline
\end{tabular}

The frequency of the third coronary artery noted in our study is comparable to the values noted in the previous studies oncadavers $[2,3,11,12$, 14]. Wide variation in the frequency of the TCA observed in previous studies may be attributed to racial differences and age [3]. Different methodologies used for the study may also contribute to the observed variations as unless specifically looked for, coronary angiograms frequently fail to visualize the third coronary artery.

The origin of TCA is also highly variable as observed in the Table 3 below.

Table 3: Comparison of the origin of the Third coronary artery in different studies.

\begin{tabular}{|l|c|c|}
\hline \multicolumn{1}{|c|}{ Author } & $\begin{array}{c}\text { Common ostium in } \\
\text { anterior aortic sinus }\end{array}$ & $\begin{array}{c}\text { Independent ostium in } \\
\text { anterior aortic sinus }\end{array}$ \\
\hline Olabu et al [3] & $16.21 \%$ & $17.56 \%$ \\
\hline Dhobale et al [10] & $2 \%$ & $30 \%$ \\
\hline Udayashankari et al [13] & $23.33 \%$ & $23.33 \%$ \\
\hline Present study & $26 \%$ & $4 \%$ \\
\hline
\end{tabular}

The illustrations seen in the texts are the frequently noted arterial pathways but the course, branching pattern of the coronary arteries exhibit wide variations [16]. The proximal coronary artery develops from the endothelial ingrowth of the peritruncal ring of the coronary vasculature. The endothelial strands from the peritruncal ring that penetrate the facing sinuses fuse whereas the endothelial strands growing towards the noncoronary sinus disappear[17]. Endothelial strands from which RCA and TCA arise may approach the anterior aortic sinus separately and then fuse with it which may explain the independent origin of the TCA from AAS.

We observed TCA bifurcating to supply the pulmonary infundibulum and upper part of the anterior wall of the right ventricle in most of the cases. However, in $6 \%$ of the cases, the TCA branched extensively to supply the pulmonary infundibulum, anterior wall of the right ventricle till the inferior border and the apex. Some of the branches reaching the inferior border passed under myocardial bridges. The area of supply of TCA also includes interventricular septum and conducting system, according to some authors $[3,10,18]$. Hence, TCA should always be taken into account in the management of arrythmias and myocardial ischemia. Dhobale et al observed double TCA in $4 \%$ of the specimens[10]. Lujinovic et al also observed double TCAs in $4 \%$ of the specimens under study while one specimen(2\%) in our study had 2 TCAs[2]. Hearts with 2 third coronary arteries may have larger area of supply and hence may contribute to a more efficient collateral circulation.

TCA larger than RCA was observed in 1 specimen in our study. Such large TCAs were seen in 8 hearts out of 150 hearts by Dhobale et al[10]. According to Olabu et al, large third coronary artery running epicardially may pose a surgical hazard during cardiac surgeries[3].

Dhobale et al observed myocardial bridges in 1 specimen $(0.66 \%)$ while Olabu et al noted myocardial bridges in 3 cases(2\%) $[3,10]$. We observed the myocardial bridges in 2 specimens $[4 \%]$ while in rest of the specimens the TCA ran epicardially.

Significant increase in collateral communications are seen in slowly evolving coronary obstruction of a single vessel [19].The degree of collateral circulation determines the prognosis of patients with advanced Coronary Artery Disease[7]. Harit Desai et al described a case where a large conus artery supplied extensive collaterals to the left and right coronary territories in the presence of advanced CAD which allowed them to carry out percutaneous intervention[5]. 
Similarly, well developed collateral circulation through TCA may allow diagnostic and therapeutic interventions in CAD patients.

The small sample size and the lack of clinical correlation are the limitations of this study. This study done on a large sample with clinical correlation may throw light on the following issues. Does the anastomotic potential of the third coronary artery vary with its caliber and origin? What is the contribution of the TCA for collateral circulation in varying degrees of coronary stenosis?

\section{CONCLUSION}

The frequency of third coronary artery observed in our study is $30 \%$. Although TCA frequently bifurcated to supply the pulmonary infundibulum and anterior wall of the right ventricle, it also reached the inferior border supplying the apex in $6 \%$ of the cases. The area of perfusion of the Third coronary artery is variable and may be more extensive than usual in some individuals. Well developed collateral circulation through TCA may allow diagnostic and therapeutic interventions in patients with coronary artery disease. The variant anatomy and the significant contribution of TCA to coronary perfusion necessitates the selective visualization and functional assessment of TCA in patients with coronary artery disease.

\section{ABBREVIATIONS}

\section{AAD - Anterior aortic sinus \\ CAD - Coronary artery disease \\ TCA - Third coronary artery \\ Conflicts of Interests: None \\ REFERENCES}

[1]. Johnson D. Heart and mediastinum. In Gray's Anatomy: The anatomical basis of clinical practice. 40th ed. Edited by Standring S. London: Elsevier Churchill Livingstone; 2005:978-980.

[2]. Almira Lujinoviæ, Fehim Ovèina , Ademir Tursiæ. Bosnian Journal Of Basic Medical Sciences 2008; 8(3): 226-229.

[3]. Olabu BO, Saidi HS, Hassanali J, Ogeng'o J. A. Prevalence and Distribution of the Third Coronary Artery in Kenyans. Int. J. M orphol 2007;25(4):851-854.
[4]. Augustín JD ,Alberca PM, Antolín RH, Vilacosta I, Leopoldo Pérez de Isla, Rodríguez E, Macaya C, Zamoranoa J.Collateral Circulation From the Conus Coronary Artery to the Anterior Descending Coronary Artery: Assessment Using Multislice Coronary Computed Tomography. Rev Esp Cardiol. 2010;63:347-51.

[5]. Harit Desai, Richard Kovach, \& Jon C. George. Coronary Perfusion via Single Patent Conus Artery in the Presence of Severe Native Artery and Coronary Bypass Graft Disease. Cath Lab Digest.2012; 20(2): 2627.

[6]. Agnieszka Mlynarska, Rafal Mlynarski, Maciej Sosnowski. Conus Artery in Coronary CT Angiography. Arch Cardiovasc Imaging. 2014;2(2):e19641.

[7]. Levin DC, Beckmann CF, Garnic JD, Carey P ,Bettmann $M A$. Frequency and clinical significance of failure to visualize the conus artery during coronary arteriography. Circulation 1981;63(4):833-837.

[8]. Aya M. Wada, Spencer G. Willet, David Bader .Coronary vessel Development $A$ unique form of vasculogenesis. Arterioscler Thromb Vasc Biol. 2003;23:2138-2145

[9]. Silva Junior GO,M iranda S WS, M andarim-De-Lacerda C. A. Origin and development of the coronary arteries. Int. J. Morphol., 27(3):891-898, 2009.

[10]. Dhobale MR, Puranik MG, Mudiraj NR,Joshi UU. Journal of Clinical and Diagnostic Research. 2015;9(10): AC01-AC04.

[11]. Apsara M P. The Third Coronary Artery: Lessons Revisited. Journal of Evolution of Medical and Dental Sciences 2014; 3(43) Page: 10704-10710.

[12]. Kalpana R. A Study On Principal Branches of Coronary Arteries In Humans. J Anat. Soc. India 2003; 52(2) 137-140.

[13]. Udaya Sankari T, Vijaya Kumar J, Saraswathi P. The anatomy of right conus artery and its clinical significance. Recent Research In Science And Technology 2011; 3(10): 30-39

[14]. Ballasteros LE ,Ramirez LM, Quintero ID, Right coronary artery anatomy: anatomical and morphometric analysis. Rev Bras Cir Cardiovasc 2011;26 (2): 230-7.

[15]. Kulkarni JP .Variant Anatomy of Coronary Arteries.2013 Heart India, 1(2)46-51

[16]. David E. Reese, Takashi Mikawa, David M. Development of the Coronary Vessel System .Circulation Research 2002;91:761-768.

[17]. Katsumi Ando, Yuji Nakajima, Toshiyuki Yamagishi, Sadamu Yamamoto, Hiroaki Nakamura. Development of Proximal Coronary Arteries in Quail Embryonic Heart. Circulation Research 2004; 94:346-352.

[18]. Lüdinghausen M , Hayakawa M, Üzel M. Arterial supply of, and arterial preponderance in the human interventricular septum, Eur J Anat 2003, 7 (2): 101115.

[19]. Giorgio baroldi, Oreste mantero ,Giuseppe. The collaterals of the coronary arteries in normal and pathologic hearts. Circulation research 195;4:223-229.

How to cite this article:
Jyothi Lakshmi G.L., Vineesh V, Dini M athew. THIRD CORONARY ARTERY: A CADAVERIC STUDY.
Int J Anat Res 2017;5(1):3410-3414. DOI: 10.16965/ ijar.2016.491

Int J Anat Res 2017, 5(1):3410-14. ISSN 2321-4287 